\title{
Role of histoacryl in controlling hemorrhage during needlescopic thoracic sypathectomy
}

\author{
Anil Gandhi \\ Correspondence: anil.gandhi@monash.edu

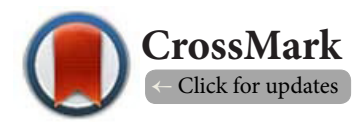 \\ Clinical School Johor Bahru, Jeffrey Cheah School of Medicine and Health Sciences, Monash University, Malaysia.
}

\begin{abstract}
Palmar hyperhidrosis has been a troublesome medical problem for many asian youth causing much discomfort and inconvenience.

Aim: Hemorrhage during the procedure is a potential complication if the ganglion is traversed by a vessel. IT is difficult to dissect the vessel away from the ganglion as the operative field is limited. WE present one case report in which hemorrhage was controlled using Histoacryl injection at the bleeding site.

Methods: 28 years old male patient underwent needlescopic thoracic sympathectomy for palmar hyperhidrosis. During the procedure while coagulating $2^{\text {nd }}$ thoracic sympathetic ganglion, one vessel which was adherent to the ganglion started bleeding profusely which could not be controlled with usual diathermy. Histoacryl was injected into the bleeding site through $2 \mathrm{~mm}$ port needle. The bleeding stopped instantaneously.

Results: The complications of this procedure are quite the same in all series published till now. Almost in one third of patients, the sympathetic chain is not clearly visible. Kao observed significant pleural adhesions and no reliable method of controlling haemorrhage. But with Injection Histoacryl the bleeding stopped immediately. The potential complication for which either a new port placement or conversion to open thoracotomy was required, was prevented by Histoacryl injection.

Conclusion: Histoacryl which was initially recommended for use in the closure of small and fresh skin wounds and later used extensively in Endoscopy rooms for bleeding duodenal/gastric ulcers can be safely used to stop the troublesome hemorrhage during needlescopic thoracic sympathectomy.
\end{abstract}

Keywords: Palmar hyperhidrosis, thoracic sympathectomy, histoacryl, hemorrhage

\section{Introduction}

Palmar Hyperhidrosis is a common disorder that interferes with the functional activities of many patients. The symptoms appear early and may persist throughout adult life.

Palmar Hyperhidrosis refractory to conservative therapy are commonly treated surgically by interruption of the sympathetic supply to the hand. In the past this was treated by posterior approach [1]. This procedure was associated with a low (25\%) incidence of complications but requires up to one week of hospitalization, is technically difficult and time consuming operation [2]. Because of this, patients even declined bilateral treatment even though they have sweating on both sides. Other therapeutic methods such as the application of topical agents like Aluminum chloride or ionophoresis-the electrical coagulation of sweat glands are used in mild cases, but the results are not satisfactory. Moreover, a regular treatment is required.

Sympathectomy developed in the mid- $19^{\text {th }}$ century, when it was learned that the autonomic nervous system runs to almost every organ, gland and muscle system in the body. It was surmised that these nerves play a role in how the body regulates many different body functions in response to changes in the external environment, and in emotion.

Thoracic sympathectomy has been indicated for hyperhidrosis since 1920, when Kotzareff showed it would cause anhidrosis. Percutaneous Radio-frequency sympathectomy is limited by its imprecise localization of the thoracic sympathetic chain. Various endoscopic procedures have been described involving 
Anil Gandhi, Chronicles of Surgery 2015,

thermo-coagulation, laser coagulation and non-video-assisted methods [3-6].

Video-assisted endoscopic Trans-axillary thoracic sympathetic ganglionectomy is the preferred treatment of choice for Palmar Hyperhidrosis. The success rate has been reported to be in the range of $87-100 \%$ with low complication rate and shorter hospital stay $[\mathbf{7}, \mathbf{8}]$. Thoracic sympathectomy by interfering with the sympathetic innervation to the sweat glands through ganglionectomy gives excellent results and prompt relief of sweating.

The complications of this procedure are quite the same in all the series published till now, namely-compensatory sweating pneumothorax, Horner's syndrome to name a few [11-14].

Hemorrhage during the procedure is a potential complication, if the ganglion is traversed by a vessel. It is difficult to dissect the vessel away from the ganglion as the operative field is limited. Significant intra-operative bleeding is an important complication described in the literature. It occurs in up to 5.3\% of patients undergoing endoscopic thoracic sympathectomy [15]. Mostly it is because of injury to the intercostal vessels which can be controlled endoscopically with cautery either by adding another port or converting a $3 \mathrm{~mm}$ port to either $5 \mathrm{~mm}$ or $10 \mathrm{~mm}$ port.

In a series reported by Kao, [16] using $2.4 \mathrm{~mm}$ operating thoracoscope, he noted that in $1 / 3^{\text {rd }}$ of cases, the sympathetic trunk was not clearly visible. He also observed significant pleural adhesions and no reliable method of controlling hemorrhage.

Histoacryl consists of monomeric n-butyl-2-cyanoacrylate, which polymerises quickly in connection with tissue fluid. It is a watery solution, which polymerizes and hardens within 20 seconds in a physiological milieu and instantaneously upon contact with blood. This makes it ideal for obliterating vessels and controlling bleeding. It is necessary to dilute it with the oily contrast agent Lipiodol, which is not only compatible with the tissue glue for dilution but also allows fluoroscopic monitoring of delivery of the substance. Histoacryl is available for topical as well as in injectable formulation. Histoacryl is indicated for the treatment of bleeding peptic ulcer disease, esophageal varices and for closure of smooth and fresh skin wounds. It has also been used for non-traumatic mesh fixation in hernia repair but it has not been described to be used for control of bleeding.

We present one case report in which Hemorrhage was a controlled using Histoacryl injection at the bleeding point.

\section{Case presentation}

23 years old male patient underwent bilateral Trans- axillary needlescopic Thoracic sympathectomy using $3 \mathrm{~mm}$ and $2 \mathrm{~mm}$ ports.

Under general anesthesia with double lumen endotracheal tube, patient was placed in the left lateral position with the arm flexed to expose the axilla. Temperature probe was fixed to both palms to record the peripheral cutaneous temperature.
The ipsilateral lung was deflated and a $3 \mathrm{~mm}$ cannula was inserted in the $4^{\text {th }}$ intercostal space in the mid-axillary line. Low flow carbon dioxide was insufflated to $10 \mathrm{~mm}$ of $\mathrm{Hg}$ pressure. Then $3 \mathrm{~mm}$ needle scope with camera (Karl Storz) was inserted to view the thoracic cavity and the sympathetic chain running horizontally over the neck of the ribs. Then $2 \mathrm{~mm}$ trocar was inserted in the $5^{\text {th }}$ intercostal space in the posterior axillary line. First rib and the stellate ganglion over it identified and preserved.

A $2 \mathrm{~mm}$ ball-tipped electro cautery was introduced through the $2 \mathrm{~mm}$ port to ablate the two ganglions over the $2^{\text {nd }}$ and $3^{\text {rd }}$ rib from superior to inferior edge. There was a small vessel adherent to the $2^{\text {nd }}$ ganglion, which in spite of all precautions started bleeding. The bleeding could not be controlled with the cautery. A suction tip was passed through the $2 \mathrm{~mm}$ port after taking out the ball tipped electro cautery probe. The suction tip was placed right on top of the bleeding vessel.

Histoacryl injection was given through the $2 \mathrm{~mm}$ port using 23-gauge disposable injection needle catheter. It contained $0.5-1.0$ cc of Histoacryl and an equal volume of Lipiodol. The bleeding stopped immediately.

The gas was allowed to escape during inflation of the lung under direct vision. Once the lung was fully inflated, needlescope and the 2 ports were removed. Chest drainage was not required. The wounds were infiltrated with $0.5 \%$ Marcaine and air tight dressing was applied. Then the patient position was changed to the right side and same steps for thoracic sympathectomy were repeated. A chest X-ray was obtained in the recovery to check for any residual pneumothorax.

\section{Discussion and conclusion}

Palmar Hyperhidrosis has been a troublesome medical problem for many Asian youth, causing much discomfort and inconvenience. It is well recognized now that surgical treatment is superior to medical therapy in the cure of the disease $[9,10]$.

In recent years Endoscopic thoracic sympathectomy has been used in many centers to treat Palmar Hyperhidrosis for its simplicity and effectiveness. The second and the third thoracic ganglion can be easily identified with vedioscope and destroyed using diathermy. In the Minimally Invasive Surgery Center, at N. U. H. we are doing Needlescopic Thoracic sympathectomy using two holes-3mm port for camera and $2 \mathrm{~mm}$ port for diathermy.

Histoacryl is a tissue adhesive composed of monomeric n-butyl-2-cyanoacrylate. It has been indicated in the closure of small and fresh skin wounds.

Presently it is being used extensively in the Endoscopy rooms throughout the world to control the bleeding from the peptic ulcer both duodenal and gastric, where initial hemostasis is not achieved with the injection of adrenaline. The results have been quite encouraging in case of bleeding duodenal/gastric ulcers. But we haven't come across any reference of its use to stop small but troublesome bleeding in laparoscopic or needlescopic surgery. 
Anil Gandhi, Chronicles of Surgery 2015,

However if one is using 3 ports one $10 \mathrm{~mm}$ and two $5 \mathrm{~mm}$ ports in $2^{\text {nd }}, 4^{\text {th }}$ and $5^{\text {th }}$ intercostal space for Thoracic sympathectomy as described by D P Robertson, then one can use the third port for hemostasis using either dissecting or grasping forceps.

But in the era of Minimally Invasive Surgery or as it is rightly called Needlescopic surgery, a needle with a Histoacryl is a better option to stop the small and troublesome bleeding than restoring to creating one more unnecessary wound.

\section{Competing interests}

The author declares that he has no competing interests.

\section{Publication history}

Editors: Shozo Yokoyama, Wakayama Medical University, Japan. Mark Berger Anderson, Robert Wood Johnson School of Medicine, USA.

EIC: Alfio Ferlito, University of Udine, Italy.

Received: 13-Feb-2015 Final Revised: 29-Mar-2015

Accepted: 15-Apr-2015 Published: 22-Apr-2015

\section{References}

1. Adar R, Kurchin A, Zweig A and Mozes M. Palmar hyperhidrosis and its surgical treatment: a report of 100 cases. Ann Surg. 1977; 186:34-41. | Article | PubMed Abstract | PubMed Full text

2. Gruszkiewicz J, Doron Y, Guilburd JN and Zaaroor M. Hyperhidrosis and its surgical treatment. Acta Neurochir (Wien). 1986; 81:128-31. | Article I PubMed

3. Chuang KS, Liou NH and Liu JC. New stereotactic technique for percutaneous thermocoagulation upper thoracic ganglionectomy in cases of palmar hyperhidrosis. Neurosurgery. 1988; 22:600-4. | Article I PubMed

4. Kuntz A. Distribution of t 6 he sympathetic rami to the brachial plexus;its relation to sympathectomy affecting the upper extremity. Arch Surg. 1927; 15:871-877. | Article

5. van Rhede van der Kloot E, Drukker J, Lemmens HA and Greep JM. The high thoracic sympathetic nerve system--its anatomic variability. J Surg Res. 1986; 40:112-9. | Article | PubMed

6. Wilkinson HA. Percutaneous radiofrequency upper thoracic sympathectomy: a new technique. Neurosurgery. 1984; 15:811-4. | Article | PubMed

7. Herbst F, Plas EG, Fugger R and Fritsch A. Endoscopic thoracic sympathectomy for primary hyperhidrosis of the upper limbs. A critical analysis and long-term results of $\mathbf{4 8 0}$ operations. Ann Surg. 1994; 220:86-90. | Article | PubMed Abstract | PubMed Full text

8. Kopelman D, Hashmonai M, Ehrenreich M, Bahous $\mathrm{H}$ and Assalia A. Upper dorsal thoracoscopic sympathectomy for palmar hyperhidrosis: improved intermediate-term results. J Vasc Surg. 1996; 24:194-9. | Article I PubMed

9. Drott C, Gothberg G and Claes G. Endoscopic transthoracic sympathectomy: an efficient and safe method for the treatment of hyperhidrosis. J Am Acad Dermatol. 1995; 33:78-81. | Article | PubMed

10. Byrne J, Walsh TN and Hederman WP. Endoscopic transthoracic electrocautery of the sympathetic chain for palmar and axillary hyperhidrosis. Br J Surg. 1990; 77:1046-9. | Article | PubMed

11. Lai YT, Yang LH, Chio CC and Chen HH. Complications in patients with palmar hyperhidrosis treated with transthoracic endoscopic sympathectomy. Neurosurgery. 1997; 41:110-3. | Article | PubMed

12. Kurchin A, Mozes $M$, Walden R and Adar R. Phantom sweating. Angiology. 1977; 28:799-802. | Article | PubMed

13. Shelly $\mathrm{CJ}$ and Florence R. Compensatory hyperhidrosis after sympathectomy. N Engl J Med. 1960; 24:1056-1058. | Article

14. Romano A, Kurchin A, Rudich R and Adar R. Ocular manifestations after upper dorsal sympathectomy. Ann Ophthalmol. 1979; 11:1083-6. | PubMed

15. Dominique Gossot, Hassan Kabiri, Raffaele Caliandro, Denis Debrosse Philippe Girard and Dominique Grunenwald. Thoracic Department, Institut Mutualiste Montsouris, Paris, France. The Annals of Thoracic Surgery. 2001; 71:1116-9.

16. Kao MC. Video endoscopic sympathectomy using a fiberoptic $\mathrm{CO}_{2}$ laser to treat palmar hyperhidrosis. Neurosurgery. 1992; 30:131-5. | Article | PubMed

\section{Citation:}

Gandhi A. Role of histoacryl in controlling hemorrhage during needlescopic thoracic sypathectomy. Chron Surg. 2015; 2:1. http://dx.doi.org/10.7243/2053-7212-3-1 